San Jose State University

SJSU ScholarWorks

Master's Theses

Master's Theses and Graduate Research

Summer 2012

\title{
The Effect of Competence, Likeability, and Sex on Performance Evaluations of Managers
}

Connie Kehn

San Jose State University

Follow this and additional works at: https://scholarworks.sjsu.edu/etd_theses

\section{Recommended Citation}

Kehn, Connie, "The Effect of Competence, Likeability, and Sex on Performance Evaluations of Managers" (2012). Master's Theses. 4195.

DOI: https://doi.org/10.31979/etd.hrzu-2du2

https://scholarworks.sjsu.edu/etd_theses/4195

This Thesis is brought to you for free and open access by the Master's Theses and Graduate Research at SJSU ScholarWorks. It has been accepted for inclusion in Master's Theses by an authorized administrator of SJSU ScholarWorks. For more information, please contact scholarworks@sjsu.edu. 
THE EFFECT OF COMPETENCE, LIKEABILITY, AND SEX ON PERFORMANCE EVALUATIONS OF MANAGERS

\author{
A Thesis \\ Presented to \\ The Faculty of the Department of Psychology \\ San José State University \\ In Partial Fulfillment \\ of the Requirements for the Degree \\ Master of Science
}

by

Connie M. Kehn

August 2012 
(C) 2012

Connie M. Kehn

ALL RIGHTS RESERVED 
The Designated Thesis Committee Approves the Thesis Titled

THE EFFECT OF COMPETENCE, LIKEABILITY, AND SEX ON PERFORMANCE

EVALUATIONS OF MANAGERS

by

Connie M. Kehn

APPROVED FOR THE DEPARTMENT OF PSYCHOLOGY

SAN JOSÉ STATE UNIVERSITY

August 2012

Dr. Megumi Hosoda, Department of Psychology

Dr. Howard Tokunaga, Department of Psychology

Dr. Arlene Asuncion, Department of Psychology 


\begin{abstract}
THE EFFECT OF COMPETENCE, LIKEABILITY, AND SEX ON PERFORMANCE EVALUATIONS OF MANAGERS

by Connie M. Kehn

The effects of competence, likeability, and sex of an upper-level manager on his or her performance evaluation and the work relationship with his or her subordinates were examined in the present study. Given that women in leadership positions are frequent victims of prejudice and discrimination, it was of a particular interest to examine how female managers would be evaluated. In a survey of 228 undergraduate students, competence was found to be an important attribute when it came to performance evaluation, whereas likeability was found to be an important attribute when it came to the work relationship. Female managers were found not to be necessarily devalued; when women managers were clearly described as competent, they were evaluated more positively than their male counterparts, regardless of their likeability levels. The results of the present study indicate that competence and likeability are more important attributes than sex to determine performance evaluation and the work relationship between supervisor and subordinate.
\end{abstract}




\section{TABLE OF CONTENTS}

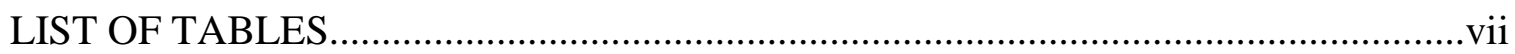

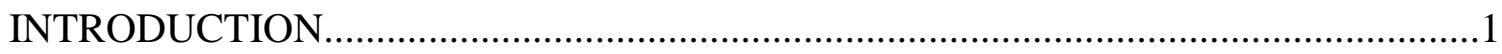

Theories Explaining Prejudice Against Female Leaders........................................4

Role congruity theory...........................................................................

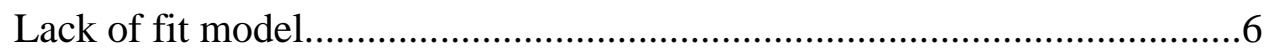

Factors Affecting Bias and Discrimination Against Women Leaders......................9

Masculinity of leadership role...............................................................

Sex distribution within the leadership role..................................................11

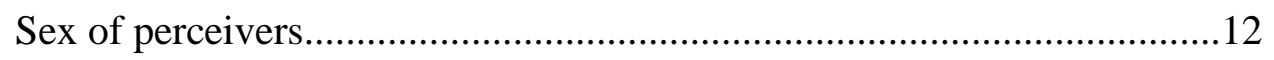

Complementing agentic actions with communal qualities........................13

Personal Likeability and its Effect on Relationships at Work................................15

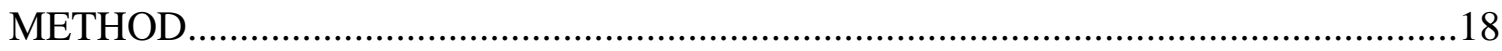

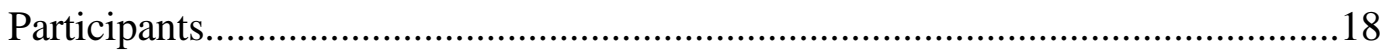

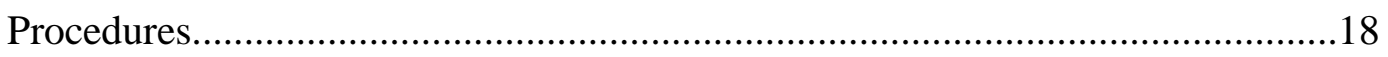

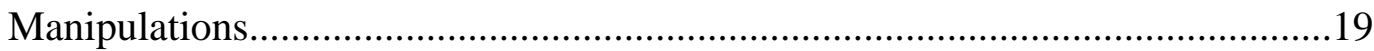

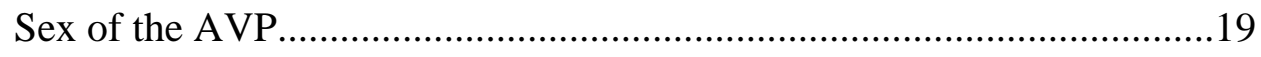

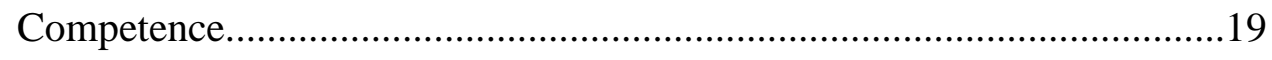

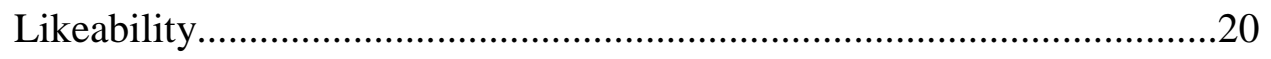

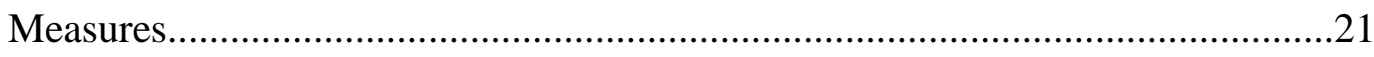

Overall work performance evaluation......................................................21

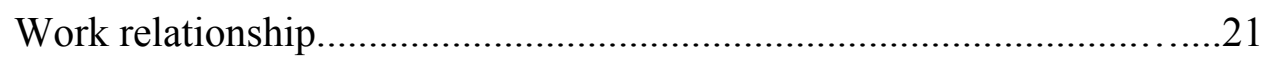


Sex-typing of the AVP position.......................................................22

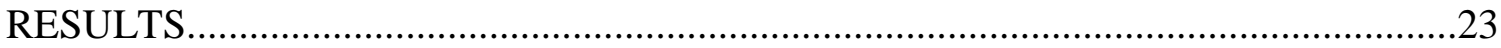

Manipulation Checks...............................................................................2 23

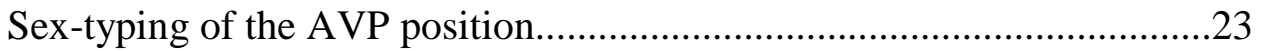

Test of Hypotheses...............................................................................2

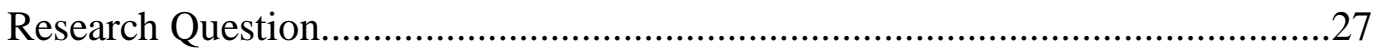

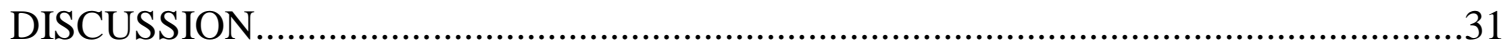

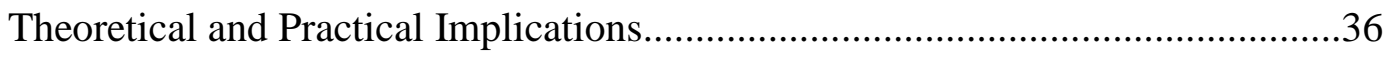

Strengths, Limitations, and Future Research.................................................38

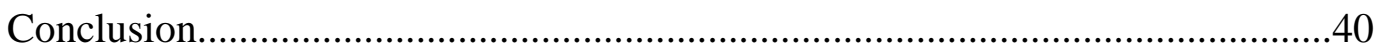

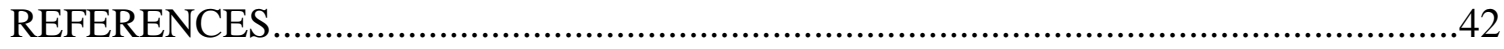




\section{LIST OF TABLES}

TABLE 1: Mean Performance Evaluation.............................................................25

TABLE 2: Mean Performance Evaluations as a Function of Competence,

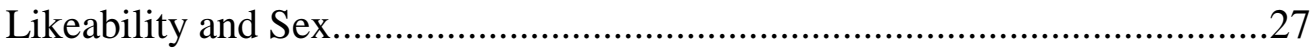

TABLE 3: Means and Standard Deviations Summary for Seek Advice Item as a Function of Likeability and Competence..........................................28

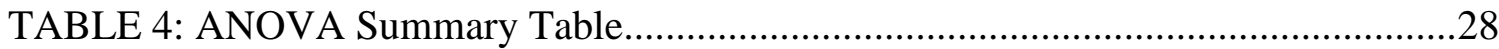

TABLE 5: Means and Standard Deviations Summary for If Supervisor Item as a Function of Competence and Likeability ...........................................29

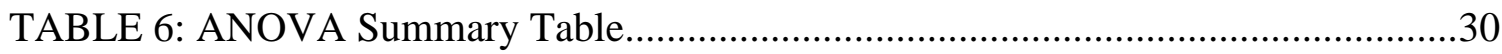




\section{Introduction}

As the $21^{\text {st }}$ century advances, we as a nation have progressed enough socially to become more accepting of females in leadership roles. For example, for the first time in our history, we recently had a female in the position of Speaker of the House of Representatives. However, women still have a long way to catch up to achieve equality. As of 2010, 51.5\% of all management positions in the United States were held by women (United States Bureau of Labor Statistics, 2011); however, there are still relatively few women occupying major leadership roles. For example, women occupy only $25.5 \%$ of chief executive positions across industries and sectors (United States Bureau of Labor Statistics, 2011). One of the reasons for the under-representation of women in higher levels of organizations is that they are often targets of prejudice and discrimination (Eagly \& Karau, 2002; Heilman, 1983).

Numerous studies have produced evidence of persistent biases against women in the workplace. Many of these biases are rooted in the concept of certain social norms being violated. Social norms are defined as an established standard of behavior shared by members of a social group to which each member is expected to conform (Dictionary.com, 2011). Specifically, the social norms women violate are gender norms (i.e., expectations about what women are like and how they should behave) triggered not only by their presence in the workplace, but possibly by the role they play within the organization. When these gender norms are violated, consciously or unconsciously, negative backlash can ensue against the "offending" woman from other organizational members. 
However, the longer the organizational member works or interacts with the woman in question, the more factors other than her sex become salient, such as her personality characteristics and level of success at her job (Heilman, 1983). Such factors might influence the evaluation of these women. Subsequently, information such as how nice the woman is or how competent she is at her job might also affect her evaluation as a manager. This is an important area to explore in order to identify factors that may reduce the amount of bias in evaluations of women in leadership roles.

While there is no research available addressing this specific issue among female leaders in the workplace, indirect evidence shows that a coworker's niceness and competence are important in working relationships. Casciaro and Lobo (2005) examined informal social networks such as those found within any organization to see how people chose their work partners. Specifically, they wanted to see, when people were forced to choose between likeability and competence, which of the two was preferred. The authors defined a competent individual as someone who knows how to do his or her job and a likeable individual as someone who is enjoyable to work with. The four resulting archetypes of work partners were the loveable star (competent and likeable), the competent jerk (competent and unlikeable), the loveable fool (incompetent and likeable), and the incompetent jerk (incompetent and unlikeable).

Casciaro and Lobo (2005) found that the loveable star was the highest in demand, but the more interesting result was that likeability played a larger role in forming work relationships than expected; the loveable fool was preferred over the competent jerk. Apparently, personal feelings of likeability were so strong that they acted as a deal 
breaker; if an individual was disliked strongly enough, his or her level of competence was irrelevant. In contrast, the highly liked individuals were sought out for whatever sliver of competence they possessed (Casciaro \& Lobo, 2005).

Casciaro and Lobo (2005) reasoned that when presented with a problem to solve, a coworker might believe that the unlikeable individual, even when viewed as highly competent, does not seem worthwhile to pursue because he or she may be brusque, condescending, or unwilling to share his or her knowledge. In contrast, the likeable individual would be more approachable, more willing to share, or at the very least be a better partner for brainstorming activities (Casciaro \& Lobo, 2005).

Although their study was based on informal social networks within organizations, their findings might also apply to manager evaluations, an area of research that has yet to be explored. Though competence is an important quality for a manager to possess in order to be successful, likeability may help increase the manager's effectiveness. This could be because a manager often works closely with his or her subordinates and interacts with them on a regular basis. If a subordinate views the manager as approachable, he or she may be likely to be more forthcoming with ideas, questions, or concerns, and therefore evaluate the manger more positively even if he or she is not highly competent. In addition to preferring to work with the likeable manager, they may also be more willing to help such a supervisor when help is needed.

Therefore, the major purpose of this study was to examine whether the results of Casciaro and Lobo (2005) apply to the evaluation of managers and, more specifically, whether their results apply to the evaluation of female managers. This study addressed 
the question of whether a manager's sex would matter when evaluating an incompetent and likeable manager or a competent and unlikeable manager.

A substantial amount of research exists on the various obstacles and biases women face in the workplace and how they affect the evaluations of female leaders in an organization. A person's stereotypes and biases are the filter through which one evaluates the world, including one's manager at work. In the sections below, literature regarding the effect of sex stereotypes on women's performance evaluations is reviewed, followed by factors that influence a perceiver's evaluation of his or her female manager, and finally how personal likeability and competence at the job might play a mitigating role in evaluating these female leaders.

\section{Theories Explaining Prejudice Against Female Leaders}

Role congruity theory. A few theories have been put forth to clarify why women are discriminated against in the workplace, particularly those in leadership positions. Eagly and Karau (2002) have developed a role congruity theory which states that the bias against female managers stems from the incongruity observers perceive between women's attributes assigned by their female gender role and the qualities believed necessary to successfully fill the leadership role.

According to Eagly and Karau (2002), gender roles are consensual beliefs about men and women's attributes (i.e., what men and women are like). In general, women are expected to possess communal attributes and qualities. That is, a woman's role dictates that she is expected to be kind, sympathetic, socially-oriented, collaborative, nurturing, and gentle (Eagly \& Johnson, 1990; Eagly \& Karau, 2002; Eagly, Makhijani, \& Klonsky, 
1992; Heilman \& Chen, 2005; Rudman \& Glick, 1999). These communal (i.e., feminine) attributes are usually contrasted with agentic (i.e., masculine) characteristics, which are attributes more strongly associated with men, such as being assertive, controlling, achievement-oriented, confident, aggressive, ambitious, and independent (Eagly \& Karau, 2002; Heilman \& Chen, 2005). However, the consensual social belief is that the leadership role requires agentic qualities (e.g., decisiveness, assertiveness) to be successful, resulting in a perceived incongruity between women's communal attributes and the agentic attributes associated with being a successful leader. Consequently, women are viewed as inherently less qualified to lead because they are believed to lack the agentic qualities necessary for success in the leadership role (Brenner, Tomkiewicz, \& Schein, 1989; Eagly \& Karau, 2002).

When women are in or aspire to be in a leadership position, they violate two types of behavioral norms, with the end result creating two respective forms of prejudice against women leaders. Eagly and Karau (2002) describe these norms as descriptive and injunctive; the combination of these two social norms creates the gender role conceived by the observer. Descriptive norms are assumptions about what the members of a group are like, and injunctive norms are beliefs about how the members of a group ought to be. The descriptive norms applied to women are attributes such as being nurturing, kind, or communal, and the associated injunctive norms refer to how women should act due to these attributes. For example, there would be no perceived incongruence if a woman in the workplace displayed nurturing attributes (descriptive norm) to her coworkers, such as speaking to her work group about the importance of family, and then initiates an office- 
wide baby shower for a coworker about to go on maternal leave (injunctive norm). However, if a different woman in the same work group was highly vocal about family life not belonging in the work place (descriptive norm violation), and refused to contribute to the group's voluntary baby shower for the pregnant coworker (injunctive norm violation), she could become the subject of discrimination or negative backlash.

When these norms are violated, the outcomes result in the following two respective forms of prejudice: first, a descriptive norm violation can result in a less positive evaluation of a woman's potential as a leader than a male because the ability to lead is stereotypically more associated with men than with women. Second, a violation of an injunctive norm can result in a less positive evaluation of a woman's actual leadership behavior than a male's actual leadership behavior because such behavior is less desirable in women than in men (Eagly \& Karau, 2002). Even if a woman is successful within the leadership role, she is not behaving as a woman should, and is therefore violating the injunctive norm. In other words, women do not have what it takes to become a leader, and they should not want to lead in the first place. The ramifications of these prejudices include reduced access to leadership roles for women than for men, more negative attitudes toward women leaders than men, and more obstacles for women to overcome in order to be successful leaders than men (Eagly \& Karau, 2002).

Lack of fit model. Closely related to role congruity theory is Heilman's lack of fit model (1983). Heilman (1983) posits that gender bias in the workplace stems from the perceived lack of fit between the attributes possessed by a job applicant or jobholder and the attributes believed to be necessary to be successful in the position (Heilman, 1983). 
Specifically, Heilman's model focuses on the perceived disparity caused by stereotypical female attributes and attributes that are believed to be necessary to perform a stereotypically masculine job successfully. The larger the perceived discrepancy between what women are believed to bring to the table and what is believed to be required to be a successful manager, the greater their chance of experiencing gender-based judgments. This perceived lack of fit causes others to expect that women will perform poorly, hence the more negative bias against them (Heilman, 1983). While Eagly and Karau (2002) focus more on stereotypes that are violated by women desiring to be in a leadership position and acting on such desires (i.e., descriptive and injunctive norms), Heilman's research centers more on the perceived lack of fit between attributes women should possess and the attributes required to be a successful leader which then leads to negative performance expectations.

Heilman's (1983) model has been used to explain bias against women in organizational decisions such as hiring, promotions, and performance evaluations. Specifically, this model posits that negative expectations against female leaders play a role in their evaluations due to the tendency to perpetuate and confirm these expectations. This inherent belief in the lack of fit is a bias that influences all information pertaining to the person in question, therefore, "negative expectations resulting from perceptions of lack of fit detrimentally affect how women are regarded and how their work is evaluated when they're in traditionally male jobs" (Lyness \& Heilman, 2006, p. 777). The degree of the lack of perceived fit can be influenced by the sex-typing of the position; the more masculine-typed the job is, the greater the lack of fit is perceived of the woman holding 
the position, and the lower the expectation of her success. The flipside of the lack of perceived fit posits that careers requiring socially stereotypical female attributes to be successful lead to the expectations of women's success in the field. Furthermore, if a position is perceived as gender-neutral, requiring attributes considered to be both masculine and feminine, it would decrease the perceived lack of fit for women or men (Heilman, 1983).

In a study on the evaluation of different levels of managers, Lyness and Heilman (2006) investigated the evaluations of both men and women in the positions of a staff manager, considered to be a more feminine position due to attributes required to be successful, and a line manager, which was perceived to be a more masculine position. It was found that female line managers were rated most negatively out of four groups, supporting their prediction that this position would be perceived as the greatest lack of fit for female managers due to its necessity for agentic/masculine attributes in order to be successful. Female line managers were perceived to be less likely to have the necessary attributes required to be successful and were expected to perform poorly, which influenced the perceiver's evaluations of them (Lyness \& Heilman, 2006). In addition, women who were promoted were found to have higher performance ratings than men who were promoted, suggesting that women need to be regarded as more stellar in their accomplishments than male counterparts to be considered equally promotable (Lyness \& Heilman, 2006).

The amount of perceived discrepancy can be influenced by the amount of stereotypes applied to the target person (Heilman, 1983). For example, when additional 
information that is more important or salient than sex is provided about a woman candidate, the sex stereotype is undermined, the bias is no longer evident, and the presumed lack of fit is reduced (Heilman, 1983). For example, if a woman is hired at an exercise machine company in a leadership position, but her new subordinates know nothing about her other than her sex, they might consider her a poor fit with the leadership position. However, after an initial meet and greet session where they learn their new leader has a background in personal training and once owned her own workout center, they know more about the woman's attributes, and the lack of perceived fit can be reduced.

To summarize, these two major theories explain prejudice and discrimination against women managers in the workplace. Though both bodies of research focus on why women leaders are discriminated against, Eagly and Karau (2002) have focused more on the perceived incongruence of fitting the female gender role into the leadership role, while Heilman posits that the lack of perceived fit leads to poor performance expectations, which then leads to prejudice and discrimination.

\section{Factors Affecting Bias and Discrimination Against Women Leaders}

In addition to the two major theories outlined above, research has revealed various factors that could influence the degree of bias and discrimination against female leaders for better or for worse.

Masculinity of leadership role. Eagly and Karau (2002) have argued that the amount of discrimination female leaders experience is a function of the level of role incongruity perceived, and that certain factors can influence the degree of perceived 
incongruity. For example, Eagly and Karau discuss how the degree of masculinity ascribed to a leadership role can influence an observer's evaluation of the leader. The more the leadership role is described in masculine terms, the greater the incongruity of the role perceived for women. In contrast, the less masculine the leadership role is described, the more congruent it is for women (Eagly \& Karau, 2002). As mentioned earlier, they argue that in leadership roles with relatively masculine definitions, female leaders can be targets of two distinct prejudices: First, women are perceived to have a lower degree of leadership ability. Secondly, to the extent that these women conform to the requirements of a leadership role, their agentic behavior will be evaluated more negatively compared with men behaving in a similar fashion.

In a meta-analysis on gender and effectiveness of leaders, Eagly, Karau, and Makhijani (1995) found that although men and women were rated as equally effective leaders overall, women were found to be more effective than men in roles defined in less masculine terms, but less effective than men in roles defined in more masculine terms. In further support of role congruity in masculine positions, it was found that the devaluation of female leaders was greater relative to male counterparts for male-dominated leadership roles (Eagly \& Karau, 2002).

One might think that in order to counteract the negative expectations and evaluations of female leaders due to the degree of masculinity associated with a specific leadership role, a possible solution might be to simply include characteristics that are both masculine/agentic and feminine/communal in a job description. Rudman and Glick 
(1999) explored this idea in their study on what they termed "feminized management," and examined how it affected women who applied for such a position.

Rudman and Glick (1999) manipulated two job descriptions to contain either masculine descriptive terms only or the same masculine terms plus additional feminine terms, which was considered to be the feminized management position. They showed videotaped interviews of potential candidates who were characterized as agentic males, communal males, agentic females, or communal females. Participants rated the potential candidates on the dimensions of competence, social skills, and hireability. The job descriptions including both agentic and communal qualities actually were found to lead to discrimination against agentic female applicants; they were considered less hireable for the feminized position than their agentic male counterparts. In contrast, the communal females were discriminated against regarding the agentic jobs more so than their communal male counterparts. Overall, the communal female applicants were rated less hireable than the agentic female applicants for both positions.

These findings supported the Rudman and Glick's (1999) predictions that agentic females would be discriminated against when the job was feminized, as well as communal females discriminated against for the masculine position. They concluded that the feminization of management job descriptions may be actually hindering and not helping women applicants by enforcing discrimination against the most competent and ambitious among them.

Sex distribution within the leadership role. Another factor that might influence the prejudice and discrimination against female leaders is the sex distribution of the 
leadership role (Eagly \& Karau, 2002); the ratio of female to male leaders on the same hierarchical tier.

Regarding the leadership role, women might have increased visibility due to a token status; there are so few women present in the leadership role that they stand out more and any behavior displayed by them is more likely to be scrutinized, thus they are more open to being perceived negatively (Eagly \& Johnson, 1990; Eagly et al., 1992). Especially in male-dominated leadership roles such as military officers, women tend to be viewed as less effective than their male counterparts. It is considered to be an even greater deviation when women pursue these particular leadership roles, and the more agentic they act within the role, the greater the negative reactions to them (Eagly \& Karau, 2002).

In a meta-analysis of sex and the evaluation of leaders, Eagly et al. (1992) found that sex distribution within a leadership role had a significant effect on the evaluation of leaders, supporting their hypothesis that the tendency for men to be evaluated more favorably than women would be more pronounced for roles occupied mainly by men compared to roles equally occupied by both men and women. In other words, a leadership role that is more congenial for men and has a tendency to be male-dominated, such as a high-ranking military officer, would yield more negative evaluations for females fulfilling this role. However, Eagly et al. found that a leadership role that was more congenial to females, such as a teacher, yielded less negative evaluations for them.

Sex of perceivers. As previously stated, the level of masculinity ascribed to the leadership role can influence a perceiver's evaluation of a manager. A factor that might 
influence this perception is the sex of a perceiver. Brenner et al. (1989) explored this in stereotyping of management roles and found a significant disparity between men and women participants in how they viewed the similarity between women and managers. Women participants tended to view successful middle managers as having attitudes, temperaments, and characteristics that could be assigned to both men and women in general, rather than solely to men. These results show that women tend to sex-type the managerial role less than their male counterparts. Consistent with these findings, Eagly (2005) and Eagly and Karau (2002) showed that men generally tended to have a more masculine concept of leadership than women, who viewed the managerial role as requiring both communal and agentic qualities.

In a meta-analysis of sex and leader evaluation, Eagly et al. (1992) found that male participants tended to evaluate female leaders more negatively than did female participants. They reasoned that men, whose sex accorded them with a higher social status, had "more to lose" if women were accepted in leadership roles, thus, they were more apt to devalue female leaders than women. Eagly et al. also noted that women showed no real bias towards the leader of either sex, and did not favor female leaders over male leaders. Additionally, those who endorse traditional gender roles have been found to rate successful women in leadership roles, particularly those perceived as more agentic than communal, more negatively than those who endorse less traditional gender roles (Eagly, 2005).

Complimenting agentic actions with communal qualities. It has been speculated that adding communal features to agentic roles might lessen negative reactions 
to women in these roles because it allows them to still fulfill their female role (Eagly \& Karau, 2002). By perceiving that the woman has still fulfilled her female gender role, the amount of role incongruence is lessened, and evaluations tend to be more positive than those of female counterparts who do not complement their agentic qualities with communal attributes. This means that complementing agentic behavior with communal attributes or actions is likely to reduce the prejudice against women. In contrast, women are less favorably evaluated when they exhibit a more masculine style of leadership behavior; this is supported by the data showing perceivers devalue female leaders more when they behave in an autocratic manner than a democratic manner (Eagly et al., 1992).

Similarly, Heilman and Okimoto (2007) assert that when women are successful in a traditionally male domain, it is not the success itself that induces negative reactions from others, but rather the implication that the woman acted agentically to achieve her success, thus violating the gender norm of female communal attributes. They demonstrated that female managers who were successful in jobs considered to be a part of the male domain were more disliked, regarded as more interpersonally hostile, and less preferred as bosses than similarly successful male managers, unless information attesting to the women's communality was shared. In other words, successful women in masculine managerial positions were evaluated less negatively if it was revealed that they maintained their femininity by exhibiting communal characteristics, while women successful in this masculine managerial position but not exhibiting communal characteristics were evaluated more negatively. Only by fulfilling both the female gender 
role and the leadership role were these women evaluated less negatively than those women fulfilling the leadership role only.

Rudman and Glick (1999) found that women who acted in a more agentic manner might be passed up for promotions or not hired because they were seen as competent yet interpersonally insensitive. Their study showed that women were held to higher standard of "niceness" than men due to stereotypic prescriptive role behavior; because women are expected to be naturally more interpersonally-oriented, it was perceived as a violation of prescriptive behavior when they acted in a more autocratic and therefore masculine manner. Because they were not seen as nice as they should be, they are viewed as not hirable; by not behaving communally, these women may be passed over for equitable male counterparts purely on the basis of personal attributes not fitting the social norm (Rudman \& Glick, 1999).

\section{Personal Likeability and its Effect on Relationships at Work}

In light of this research regarding potential bias against women in leadership positions in the workplace, what other factors could influence a perceiver's evaluation of female leaders? Can a personal attribute such as likeability affect managerial evaluation? Likeability as an evaluation factor has not really been studied for managers, let alone specifically for female managers; Casciaro and Lobo's (2005) study focused on likeability tempering evaluations in work relationships with coworkers, but not for managers. A very small number of studies have shown how successful female leaders could receive positive evaluations. For example, Heilman and Okimoto (2007) demonstrated that only when women leaders displayed evidence of fulfilling both their 
gender and leadership roles were they evaluated more positively compared to only fulfilling the leadership role. Rudman and Glick (1999) showed that when competent women applying for leadership positions showed agentic behavior, they were discriminated against for violating their communal female role because they were perceived as being not nice enough.

Will these patterns also apply to the evaluation of female managers who differ on likeability? Could a likeable and competent female manager fulfilling both the gender and leadership roles be less negatively evaluated than a likeable and competent male manager for showing signs of both agentic and communal behaviors? Would there be a difference in evaluation between competent and unlikeable male managers and their female counterparts?

Though it is predicted that a likeable and competent manager will be the most preferred manager in general, the research reviewed above points to how women are evaluated differently than men for various reasons, and in general more negatively. Because women are expected to behave communally, and can be viewed as interpersonally hostile when they do not behave accordingly, it is predicted that women managers will be evaluated less favorably when they are unlikeable and competent than their male counterparts because the communal (i.e., likeable) nature is expected of the women more than of the men. Therefore, the hypotheses in this study are as follows: Hypothesis 1: Managers viewed as competent and likeable will be the highest evaluated of all groups, followed by incompetent and likeable managers, then 
competent and unlikeable managers, and lastly incompetent and unlikeable managers.

Hypothesis 2: Competent and unlikeable female managers viewed as will be more negatively evaluated than competent and unlikeable male managers.

Hypothesis 3: Female managers viewed as incompetent and unlikeable will be rated more negatively than male managers perceived as incompetent and unlikeable, showing that women who violate both gender role and leadership role expectations will have the most negative evaluations.

Based on Casciaro and Lobo's (2005) findings on work relationships, we posited the following research question:

Research question: Is the work relationship between a subordinate and his or her manager affected by the manager's sex, competence, or likeability? 


\section{Method}

\section{Participants}

The sample consisted of 228 undergraduate students in a large state university located in northern California. It consisted of $59 \%$ females $(n=134)$ and $41 \%$ males $(n=$ 93). The ethnic composition of the sample was diverse; $39 \%(n=87)$ identified themselves as Caucasian, 27\% $(n=62)$ as Asian American, 19\% $(n=42)$ as Latino/a, and 6\% $(n=13)$ as African American, and 9\% $(n=20)$ as "Other." Participants ranged in age from 18 to 55 years old, with a mean age of 23.14 years $(S D=5.26)$. At the time of data collection, the majority of participants $(71 \%, n=161)$ were working at least parttime, with work experience averaging out to be 5.83 years $(S D=4.94)$.

\section{Procedures}

With the permission of instructors, data were collected on-site in undergraduate business classes. A female experimenter informed the classes that the study was about the perceptions and evaluations of upper management individuals in a hypothetical company. Participants were then asked to evaluate the Assistant Vice President (AVP) of Sales of a hypothetical company in terms of the AVP's personal attributes and performance. The experimenter distributed packets that contained a consent form, an instruction sheet, a description of the hypothetical company, a job description, a performance review of an AVP, and a questionnaire.

The hypothetical company was described as an international corporation that provided an assortment of high-quality, one-of-a-kind sports equipment, and as being well known for producing well-designed and finely crafted products. The responsibilities 
of the AVP of Sales in the job description included being in charge of directing the headquarters' sales division and assigned sales territories, setting sales goals, overseeing regional and local sales managers and their staff, maintaining contact with dealers and distributors, advising sales representatives on ways to improve their sales performances, analyzing sales data, and monitoring customer trends in order to determine sales potential and inventory requirements.

Some personal attributes required for the AVP position included organizational and general business skills, knowledge of marketing and administration, and the ability to build trusting relationships with customers and staff alike. For the present study, the job description was written to be gender-neutral in regards to attributes required for the position, using terms like "knowledge of marketing and administration," "good interpersonal skills," "organizational and business skills," and "sensitivity to the concerns of others." After participants filled out the questionnaire that measured overall performance evaluation, the experimenter gave them a written debriefing sheet that described the purpose of the study.

\section{Manipulations}

Sex of the AVP. The sex of the AVP was manipulated by assigning either a male (Mike) or female (Jennifer) name to each AVP description.

Competence. Both competence and likeability variables were manipulated in the form of the information provided on the performance review of the AVP. Competence of the AVP was manipulated by modifying Heilman, Wallen, Fuchs, and Tamkins' experimental material (2004). 
The competent condition described the AVP as:

Mike (Jennifer) Smith has been the AVP of Sales for 5 years and has just undergone the company-wide annual performance review. Mike (Jennifer) was highly praised for his (her) sales volume figures, number of new client accounts, and actual dollars earned. Mike (Jennifer) has been identified as one of a small group of rising stars. Mike's (Jennifer's) performance is in the top $10 \%$ of all the Assistant Vice Presidents (AVP) of Sales company-wide.

The incompetent conditions described the APV as:

Mike (Jennifer) Smith has been the AVP for Sales for 5 years and has just undergone the company-wide annual performance review. Mike (Jennifer) was evaluated by all reviewers who agreed that Mike's (Jennifer's) performance fluctuates with regard to his (her) sales volume figures, number of new client accounts, and actual dollars earned. Mike (Jennifer) barely meets the quota deadlines. Mike's (Jennifer's) performance is in the bottom $30 \%$ of all the Assistant Vice Presidents (AVP) of Sales company-wide.

Likeability. Likeability of the AVP was also manipulated by modifying Heilman et al.'s experimental material (2004). Information regarding the interpersonal skills of the AVP was embedded in the above performance evaluation information. 
In the likeable condition, the AVP was described as:

Mike's (Jennifer's) staff and fellow executives have all

commented on how great his (her) interpersonal skills are. Mike

(Jennifer) is liked by his (her) staff and the Penguin Sports

Equipment customers. Mike (Jennifer) always acknowledges his

(her) staff's effort and goes out of his (her) way to support them.

The unlikeable condition described the AVP as:

Around the office it has been said that Mike (Jennifer) will

sometimes do unethical things to complete a sale and obtain new

clients, and is sometimes rude, opinionated, and insensitive.

\section{Measures}

Overall performance evaluation. Overall performance evaluation of the AVP was measured with five items on a 7-point Likert-type scale $(1=$ very bad, $7=$ very good). Sample items include "How would you rate Jennifer's (Mike's) ability to perform the job described?" and "How successful do you think Jennifer (Mike) will be in this organization?" Higher scores indicate a more positive overall performance evaluation ( $\alpha$ $=.93)$.

Work relationship. For exploratory purposes, the hypothetical work relationship between the participant and the AVP was measured by two items on a 7-point Likert-type scale $(1=$ not at all, $7=$ very $m u c h)$. Participants were asked to imagine that the target AVP was their own supervisor and then to indicate the extent to which they would like to 
work for the APV and the extent to which they would seek help or advice from the AVP if they had an issue or problem with their job.

Sex-typing of the AVP position. Participants were asked which sex was suited for the AVP position on a 3-point Likert-type scale $(1=$ male, $2=$ female, $3=$ either male or female). 


\section{Results}

\section{Manipulation Checks}

Results of a 2 (sex of AVP: male vs. female) x 2 (competence: incompetent vs. competent) x 2 (likeability: unlikeable vs. likeable) ANOVA supported the effectiveness of the competence manipulation. The AVPs portrayed as competent $(M=5.48, S D=.99)$ were perceived as more competent than the AVPs portrayed as incompetent $(M=3.48$, $S D=1.13), F(1,220)=229.38, p<.001, \eta^{2}=.51$.

Results of a 2 (sex of AVP: male vs. female) x 2 (competence: incompetent vs. competent) x 2 (likeability: unlikeable vs. likeable) ANOVA also supported the effectiveness of the likeability manipulation. The AVPs portrayed as likeable $(M=5.92$, $S D=.76)$ were perceived as more likeable than the AVPs portrayed as unlikeable $(M=$ $3.31, S D=1.05), F(1,220)=526.22, p<.001, \eta^{2}=.71$

Sex-typing of the AVP position. In the job description, the AVP position was made gender-neutral. Results of the $\chi^{2}$ test showed that participants did indeed view the job description as gender-neutral, $\chi^{2}(2, N=223)=293.85$, with the majority of participants $(85.5 \%)$ perceiving the position of the AVP to be suited for either male or female, $5.7 \%$ of participants viewing the position as being suited for female, and $6.6 \%$ of participants viewing the position as being suited for male. These results show the majority of participants viewed the job description as gender-neutral as intended.

\section{Tests of Hypotheses}

Hypothesis 1 predicted that likeable and competent managers would receive the most positive evaluations, followed by incompetent and likeable managers, then 
competent and unlikeable managers, and lastly incompetent and unlikeable managers. Means and standard deviations of performance evaluations as a function of the competence and likeability of AVPs are shown in Table 1. Table 1 shows that competent and likeable AVPs were rated most favorably, followed by competent and unlikeable AVPs, and incompetent and likeable AVPs. Incompetent and unlikeable AVPs were rated least favorably. The hypothesis was tested using multiple independent measures ttests with a Type I error rate of .05. Results showed that the competent and likeable AVPs $(M=6.02, S D=80)$ were evaluated significantly more favorably than the incompetent and likeable AVPs $(M=4.23, S D=.93), t(112)=11.01, p<.001$. The incompetent and likeable AVPs were evaluated significantly less favorably than the competent and unlikeable AVPs $(M=5.33, S D=.96), t(106)=6.03, p<.001$. Finally, the competent and unlikeable AVPs were evaluated significantly more favorably than the incompetent and unlikeable AVPs, $(M=3.07, S D=1.06), t(110)=11.77, p<.001$.

Consistent with the hypothesis, the competent and likeable AVPs received the most positive performance evaluations and the incompetent and unlikeable AVPs received the least favorable performance evaluations. However, the competent and unlikeable AVPs received the second highest positive performance evaluations, followed by the incompetent and likeable AVPs. These results partially supported Hypothesis 1 and indicated that competence was more important than likeability when it came to performance evaluations of managers. 
Table 1

Mean Performance Evaluations

\begin{tabular}{lccr}
\hline Condition & $N$ & $M$ & $S D$ \\
\hline Competent and Likeable & 59 & 6.02 & .80 \\
Incompetent and Likeable & 55 & 4.23 & .93 \\
Competent and Unlikeable & 53 & 5.33 & .96 \\
Incompetent and Unlikeable & 59 & 3.07 & 1.06 \\
\hline
\end{tabular}

Table 2 displays means and standard deviations of performance evaluations as a function of the competence, likeability, and sex of the AVP. Hypothesis 2 predicted that competent and unlikeable female AVPs would be more negatively evaluated than competent and unlikeable male AVPs. This hypothesis was tested with an independent measures t-test with a Type I error rate of .05 by comparing the means of overall performance evaluations between the competent and unlikeable female AVPs and their male counterparts. Unexpectedly, results showed that the competent and unlikeable female AVP's performance $(M=5.63, S D=.88)$ was evaluated significantly more favorably than was the competent and unlikeable male AVP's performance $(M=5.04$, $S D=.97), t(51)=2.30, p<.05$. This result was the opposite of what was predicted. Thus, Hypothesis 2 was not supported.

Hypothesis 3 postulated that female AVPs viewed as incompetent and unlikeable would be more negatively rated than their incompetent and unlikeable male counterparts. This hypothesis was tested with an independent measures t-test with a Type I error rate of .05 by comparing the means of overall performance evaluations between the incompetent and unlikeable female AVP and her male counterpart. Results showed that although the 
incompetent and unlikeable female AVP received lower performance rating $(M=2.98$, $S D=1.20)$ than did her male counterpart $(M=3.16, S D=.92)$, there was no significant difference between them $t(57)=-.65, p=.52$. Therefore, Hypothesis 3 was not supported.

We also examined if there was a difference on performance ratings between female and male AVPs for other combinations of competence and likeability. Female AVPs $(M=6.33, S D=.68)$ were rated significantly more positively than were male AVPs $(M=5.75, S D=.80)$ when they were described as competent and likeable, $t(57)=$ 2.98, $p<.05$, and when they were described as competent and unlikeable (female AVPs $M=5.63, S D=.88$, male AVPs $M=5.04, S D=.97), t(51)=2.30, p<.05$. These results indicated that when female AVPs were described as competent, they were rated as performing better than their male counterparts, regardless of whether they were likeable or not. However, female and male AVPs did not differ on performance ratings when they were described as incompetent and likeable (female AVPs $M=4.38, S D=.78$, male AVPs $M=4.10, S D=1.04), t(53)=1.15, p=.26$, and when they were incompetent and unlikeable (female AVPs $M=2.98, S D=1.20$, male AVPs $M=3.16, S D=.91$ ), $t(57)=$ -.65 $p=.52$. As can be seen from the table, incompetent and unlikeable AVPs were evaluated most negatively, regardless of sex. When it came to evaluating overall performance of managers, competence appeared to be more important than likeability; this appeared to be true for both men and women AVPs. 
Table 2

Means of Performance Evaluations as a Function of Competence, Likeability, and Sex of AVP

\begin{tabular}{|c|c|c|c|c|c|c|c|}
\hline \multirow[b]{2}{*}{ Condition } & \multicolumn{3}{|c|}{ Female } & \multicolumn{3}{|c|}{ Male } & \multirow[b]{2}{*}{$t$} \\
\hline & $n$ & $M$ & $S D$ & $n$ & $M$ & $S D$ & \\
\hline Competent and likeable & 27 & 6.33 & .68 & 32 & 5.75 & .80 & $2.98 *$ \\
\hline Competent and unlikeable & 26 & 5.63 & .88 & 27 & 5.04 & .97 & $2.30 *$ \\
\hline Incompetent and likeable & 26 & 4.38 & .28 & 29 & 4.10 & 1.04 & 1.15 \\
\hline Incompetent and unlikeable & 29 & 2.98 & 1.20 & 30 & 3.16 & .91 & -.65 \\
\hline
\end{tabular}

Note: $* p<.05$

\section{Research Question}

For exploratory purposes, we tested if sex, competence, and likeability of AVPs would have an effect on their work relationships with their subordinates. As mentioned earlier, participants were asked to assume if the target AVP were their supervisor and to indicate (a) how much they would like to work for the AVP and (b) how likely they would go to him or her for help or advice if they had a problem or issue with their job.

A 2 (sex of AVP: male vs. female) x 2 (competence: incompetent vs. competent) x 2 (likeability: unlikeable vs. likeable) ANOVA was conducted for each question. When asked how likely it was that participants would seek advice from the AVP for a problem or issue with their job, the analysis yielded only a main effect for competence, $F(1,220)=9.64, p<.05, \eta^{2}=.04$, and likeability, $F(1,220)=193.21, p<.001, \eta^{2}=.47$. Means and standard deviations appear in Table 3. An ANOVA summary table appears in Table 4. 
Participants reported that they would seek advice more from competent AVPs $(M$ $=4.47, S D=1.88)$ than incompetent AVPs $(M=3.79, S D=2.10)$ and that they would seek advice more from likeable AVPs $(M=5.47, S D=1.39)$ than from unlikeable AVPs $(M=2.74, S D=1.59)$. Given the effect size associated with likeability $\left(\eta^{2}=.47\right)$ was much stronger than the one associated with competence $\left(\eta^{2}=.04\right)$, when participants were to seek advice from their supervisor, likeability acted as a more important factor than competence.

Table 3

Means and Standard Deviations Summary for Seek Advice Item as a Function of Likeability and Competence

\begin{tabular}{|c|c|c|c|c|c|c|c|c|c|}
\hline \multirow[b]{2}{*}{ Condition } & \multicolumn{3}{|c|}{ Competent } & \multicolumn{3}{|c|}{ Incompetent } & \multicolumn{3}{|c|}{ Total } \\
\hline & $n$ & $M$ & $S D$ & $n$ & $M$ & $S D$ & $n$ & $M$ & $S D$ \\
\hline Likeable & 59 & 5.64 & 1.26 & 57 & 5.28 & 1.50 & 116 & 5.47 & 1.39 \\
\hline Unlikeable & 53 & 3.17 & 1.58 & 59 & 2.36 & 1.51 & 112 & 2.74 & 1.59 \\
\hline Total & 112 & 4.47 & 1.88 & 116 & 3.79 & 2.10 & & & \\
\hline
\end{tabular}

Table 4 ANOVA Summary Table

\begin{tabular}{lrrrr}
\hline Source & SS & df & MS & F \\
\hline Sex & 1.75 & 1 & 1.75 & .82 \\
Competence & 20.63 & 1 & 20.63 & $9.64^{*}$ \\
Likeability & 413.68 & 1 & 413.68 & $193.21^{*}$ \\
Sex X Competence & 5.17 & 1 & 5.17 & 2.41 \\
Sex X Likeability & .24 & 1 & .24 & .11 \\
Competence X Likeability & 2.67 & 1 & 2.67 & 1.24 \\
Sex X Competence X Likeability & .05 & 1 & .05 & .02 \\
Error & 471.05 & 220 & 21.41 & \\
\hline
\end{tabular}

Note: $* p<.05$ 
When asked how much participants would like it if the target AVP were their supervisor, results of a 2 (sex of AVP: male vs. female)) x 2 (competence: incompetent vs. competent) x 2 (likeability: unlikeable vs. likeable) ANOVA showed main effects for sex, $F(1,220)=5.51, p<.05, \eta^{2}=.02$, competence, $F(1,220)=14.64, p<.001, \eta^{2}=.06$, and likeability, $F(1,220)=296.38, p<.001, \eta^{2}=.57$. Means and standard deviations appear in Table 5. An ANOVA summary table appears in Table 6. Participants reported they would prefer a female AVP $(M=4.14, S D=2.18)$ over a male AVP $(M=3.83, S D$ $=1.97$ ) to be their supervisor. Participants also reported that they would prefer an AVP to be their supervisor more if the AVP was competent $(M=4.38, S D=1.96)$ than incompetent $(M=3.59, S D=2.19)$. Likewise, participants reported that they would prefer an AVP to be their supervisor more if he or she was likeable $(M=5.49, S D=1.37)$ than unlikeable AVPs $(M=2.41, S D=1.41)$. Given the effect size associated with likeability $\left(\eta^{2}=.57\right)$ was much stronger than the one associated with competence $\left(\eta^{2}=\right.$ $.06)$ and sex of AVPs $\left(\eta^{2}=.02\right)$, when participants chose the supervisor they would prefer to have, likeability acted as a more important factor than competence or sex of the AVP.

Table 5

Means and Standard Deviations Summary of If Supervisor Item as a Function of Competence and Likeability

\begin{tabular}{lccccccrrr} 
& \multicolumn{3}{c}{ Competent } & \multicolumn{3}{c}{ Incompetent } & \multicolumn{3}{c}{ Total } \\
\cline { 2 - 10 } Condition & $N$ & $M$ & $S D$ & $N$ & $M$ & $S D$ & $N$ & $M$ & $S D$ \\
\hline Likeable & 59 & 5.76 & 1.15 & 57 & 5.21 & 1.52 & 116 & 5.49 & 1.37 \\
& & & & & & & & & \\
Unlikeable & 53 & 2.83 & 1.45 & 59 & 2.03 & 1.27 & 112 & 2.41 & 1.41 \\
& & & & & & & & & \\
\hline Total & 112 & 4.38 & 1.96 & 116 & 3.59 & 2.12 & & &
\end{tabular}


Table 6

ANOVA Summary Table

\begin{tabular}{lrrrr}
\hline Source & SS & df & MS & F \\
\hline Sex & 9.93 & 1 & 9.93 & $5.51^{*}$ \\
Competence & 26.39 & 1 & 26.39 & $14.64^{*}$ \\
Likeability & 534.18 & 1 & 534.18 & $296.38^{*}$ \\
Sex X Competence & 2.84 & 1 & 2.84 & 1.58 \\
Sex X Likeability & .05 & 1 & .05 & .03 \\
Competence X Likeability & .82 & 1 & .82 & .45 \\
Sex X Competence X Likeability & .53 & 1 & .53 & .30 \\
Error & 396.52 & 220 & 1.80 & \\
\hline
\end{tabular}

Note: ${ }^{*} p<.05$ 


\section{Discussion}

Although women have come to be more accepted in leadership roles recently, the near four-to-one ratio of men to women occupying chief executive role positions (United States Bureau of Labor Statistics, 2011) indicates that men and women are still not perceived as equally qualified to occupy senior leadership roles. A review of the literature points to the prejudices and discrimination women face in the workplace as one of the reasons for their under-representation in higher levels of an organization (Eagly \& Karau, 2002; Heilman, 1983).

However, researchers have been identifying some factors that might reduce prejudice against female leaders. For example, Heilman (1983) argues that the longer a woman works or interacts with other organizational members, other factors (e.g., her personality characteristics, level of success at her job) become more salient than her sex. If such factors influence the evaluation of these women, it is important to identify other factors that may reduce the amount of bias in evaluations of women in leadership roles. These factors might include information about personal attributes such as the level of competence or likeability of the target person.

Casciaro and Lobo (2005) examined informal social networks within multiple organizations to see how people chose their work partners and found that likeability played a larger role in work relationships than competence; the likeable and incompetent worker was preferred over the unlikeable and competent worker. As this is a previously unexplored topic in regards to evaluating managers, the present study was designed to examine if Casciaro and Lobo's results apply to the performance evaluation of a 
supervisor. Specifically, this study was conducted in order to determine if a person's sex, level of competence, or level of likeability could affect his or her performance evaluation in a managerial position. For exploratory purposes, we also examined how a manager's level of competence and likeability and his or her sex would affect the work relationship between the manager and his or her subordinates.

Hypothesis 1 predicted that likeable and competent managers would receive the most positive evaluations, followed by incompetent and likeable managers, then competent and unlikeable managers, and lastly incompetent and unlikeable managers. Results showed that they were not ranked as predicted; the most positive evaluations were for the competent and likeable managers, followed by the competent and unlikeable managers, then the incompetent and likeable managers, and finally the incompetent and unlikeable managers. Therefore, Hypothesis 1 was partially supported. These results suggested that competence was an important factor in evaluating an upper-level manager's performance.

One reason that the results of the present study were not consistent with those of Casciaro and Lobo (2005) might be that they focused on work relationships on a coworker level and the present study focused on the evaluation of overall performance on an upper-managerial level. When evaluating performance, participants valued competence more than likeability. This may indicate that one's supervisor plays a more crucial role in an employee's overall experience and welfare at an organization than a coworker in terms of performance evaluation and the assignment of job tasks, and 
perhaps an employee would value a supervisor's level of competence in these matters rather than their level of likeability.

Hypothesis 2 postulated that female managers viewed as competent and unlikeable would be more negatively evaluated than male managers perceived as competent and unlikeable. Hypothesis 2 was not supported. Instead, competent and unlikeable female AVPs were rated more positively than their male counterparts. These results are not consistent with past research (Eagly \& Johnson, 1990; Eagly \& Karau, 2002; Eagly, Makhijani, \& Klonsky, 1992; Heilman \& Chen, 2005; Rudman \& Glick, 1999), which showed that female managers tended to be evaluated more negatively than male managers regarding performance evaluations, especially when they violated female gender roles. Present results indicated that participants might have paid more attention to the competence information than the likeability information of AVPs when evaluating their performance and that interpersonally-related information (i.e., unlikeable) may not play an important role in evaluating a manager's performance.

Hypothesis 3 stated that incompetent and unlikeable female managers would be rated more negatively than their incompetent and unlikeable male counterparts. Although incompetent and unlikeable female AVPs were rated lower than their male counterparts, the difference was not statistically significant. Thus, this hypothesis was not supported. Furthermore, competent female AVPs' performances were rated higher than their male counterparts, regardless of the level of likeability. When taken together, the present study showed that female managers were not devalued. In some situations, their performance was rated more favorably than their male counterparts. 
Of the many reasons for the lack of devaluation of female AVPs' performance in the present study, the first could be because of the characteristics of the sample. More than $80 \%$ of the participants in the present study were aged 25 or younger, making them a part of the population known as Generation Y. Research has shown that Generation Y individuals tend to view women's roles in the workplace differently than older generations (Twenge \& Campbell, 2008). Generation Y individuals see as much similarity between "women" and "manager" as between "male" and "manager," viewing women as more agentic and assertive in general, which leads to less perceived incongruence between the female gender role and the leadership role (Twenge \& Campbell, 2008). In addition, since women now occupy more than $50 \%$ of managerial positions in the United States (United States Bureau of Labor Statistics, 2011), it is speculated that Generation Y workers could simply be more used to seeing women in leadership positions than previous generations, which may lead to less perceived role incongruence for female leaders for them. This might explain the finding that participants preferred female AVP as their supervisor over male AVPs.

Another reason for the lack of devaluation of female managers could be due to the gender-neutral nature of the job description. Although an AVP of Sales for an international sports equipment company sounds masculine in nature, the attributes listed in the job description included both agentic and communal qualities. This argument is consistent with Eagly and Karau (2002) who found that supplementing agentic qualities with communal features in a job description lessened the bias against women filling these positions because it allowed them to stay true to both their female gender role as well as 
the leadership role. Perhaps if the position had been described in a more masculine manner, then the role incongruency would be far more pronounced for a woman than for a man, and thus the women's performance appraisals would have been be more negative than their male counterparts' evaluations.

Finally, the more positive evaluation of competent female AVPs' performance than their male counterparts might be due to the information that these women's performance was stellar (top 10\%). Participants are probably aware of the fact that women have to work harder to reach the upper levels of organizations than men. Therefore, competent women's undeniably superior performance information might have led their performance appraisals to be much higher than their male counterparts. Although this interpretation is speculative, it is somewhat consistent with Lyness and Heilman's (2006) findings that showed that women who were promoted to managerial positions received higher performance evaluations than did men, implying that women must perform exceptionally well in order to be considered equal to their male counterparts.

Results from exploring the participants' work relationship with the AVPs in question differed from work performance evaluations of these AVPs. That is, participants valued likeability more highly than competence in their work relationship with their supervisor. These results are consistent with Casciaro and Lobo's (2005) findings that likeability was indeed more highly valued in work relationships than competence. 
Overall, the present study demonstrated that competence was important when it came to a supervisor's performance evaluation and likeability was important when it came to a supervisor-subordinate relationship. These findings seem to reflect the inherent human desire to have the best of both worlds: when forced to choose, we would rather have a supervisor we find likeable to work with rather than competent at his or her job, but when it comes to his or her performance evaluation, we place more value on his or her level of competence than likeability. We have interpreted these results to mean that managers need to be both competent and likeable in order to be successful in their jobs because different aspects of a managerial position require both interpersonal skills for supervisory tasks (i.e., likeability) as well as competence for other duties such as training, mentoring, and coordinating subordinates. Therefore, a manager who has both competent and likeable qualities is likely to make the best and most desirable manager, both to work for and work with.

\section{Theoretical and Practical Implications}

Results of the present study are consistent with those of Eagly and Karau (2002) that found that the less masculine the leadership role was described, the more congruent it was for women. By constructing the job description to be gender-neutral, including both agentic and communal attributes, performance evaluations reflected that participants probably did not perceive a high level of role incongruence for female AVPs. Present results also supported Eagly et al.'s (1995) findings that although overall males and females were rated as equally effective leaders, women were found to be more effective than men in roles defined in less masculine terms, but less effective than men in roles 
defined in more masculine terms. Perhaps if for future research the job description is deliberately masculine-skewed, we might find that female AVPs are rated more negatively in general. However, if the job description is constructed to be neutral, requiring both agentic and communal attributes, and a woman is shown to be capable of doing the job successfully, less bias against her is likely to occur.

Furthermore, Heilman (1983) has asserted that when additional information is provided about a woman that is more important than her sex, the sex stereotype is undermined and bias against her is no longer evident, hence reducing the lack of perceived fit. The results of the present study add to the literature that competence and likeability of a person is information that is more important than the person's sex in determining his or her performance appraisals and work relationships.

Some practical implications of this study could be that women might face less evaluation bias when occupying leadership roles when they are shown to be competent and when their potential subordinates are members of Generation Y. Also, women may face less discrimination when occupying leadership roles whose job descriptions include the need for both communal and agentic attributes. Finally, results from the present study suggest that job candidates for managerial positions, regardless of their sex, should keep in mind the importance of both likeability and competence as attributes to highlight in order to emphasize their well-roundedness as a manager and potential to be successful in a leadership role. 


\section{Strengths, Limitations, and Future Research}

Past research has been ambiguous about the role likeability plays in the evaluation of a manager's performance and relationship with his or her subordinates. A strength of the present study is the finding that likeability played an important role, especially in work relationships. The only other piece of research relating to this finding is that of Casciaro and Lobo (2005), which examined solely work relationships among coworkers, and not between managers and their subordinates. In particular, our finding that female managers who were perceived as competent were given higher performance evaluations than their male manager counterparts, regardless of the level of likeability, adds an interesting new element to research regarding women leaders in the workplace.

Regarding limitations of the present study, one concern could be the use of college students as participants in experimental research on personnel-related decision making because the results of the present study may not be generalizable for people who actually make these kinds of personnel decisions in a practical organizational context (Gordon, Slade, \& Schmitt, 1986; Stone, Stone, \& Dipboye, 1992). While some have argued that college students can not stand in to answer for actual decision makers in organizations (Gordon et al., 1986), other research has shown that student ratings of job applicants are almost identical to ratings performed by professional interviewers (Bernstein, Hakel, \& Harlan, 1975). Given that the majority of the present sample $(70.6 \%)$ was employed at the time of their participation and more than $15 \%$ of the participants had more than 10 years of work experience, most participants had some practical work experience to draw from when responding to the study's questions. 
Nevertheless, additional research is needed to determine the external validity of these findings using actual decision makers in the organizations.

Given that the majority of the participants were young (25 years or younger), future research should attempt to expand a sample that also includes those who are older in order to capture a more realistic picture of how women leaders are viewed by members of that age group. These older participants may hold more traditional views on women in the workplace, which may affect their evaluations of female managers, thus yielding more robust data.

Though the manipulations of both competence and likeability were successful, they may have been too strongly manipulated. Previous research has shown that stereotypes are strongest and most influential in ambiguous situations (Fiske, 1998), and particularly in situations where an individual's qualifications for a position are unclear, discrimination is most likely to occur (Dovidio \& Gaertner, 2000). Given these findings, perhaps the lack of discrimination or bias against women AVPs in the present study may have been due to the too strong manipulation of these variables; because the manipulation for competence and likeability were so strong, it might have washed out any ambiguity that would have led to discrimination based on the sex of AVPs. A solution to this may be to have fewer items that manipulate the level of competence or likeability portrayed in order to heighten the ambiguity of the situation and bring more focus on the AVP's sex. Future researchers should keep this in mind when manipulating variables of interest. In addition, researchers should manipulate a job description to be deliberately gender-skewed, whether it is male or female, rather than gender-neutral as in this current 
study. Because there was no ambiguity in the job description, this might also be why there were no gender interaction effects. Researchers could replace the agentic qualities with communal qualities for a fully feminine-skewed job description, or vice versa. For example, rather than focusing on the need for interpersonal skills for building relationships with both customers and subordinates, the job description could focus more on the need for "dominant and aggressive business skills" or the need for the AVP to have a "competitive and independent nature."

\section{Conclusion}

This study was conducted in order to evaluate how personal attributes such as competence and likeability would affect a supervisor's performance evaluation, and to examine if the supervisor's gender would also affect his or her evaluation. This was an important topic to examine to further understand and identify factors that influence an evaluation of a supervisor and in particular a female supervisor. In addition to the hypotheses that were tested, this study also explored the role that competence and likeability played in the working relationship between a subordinate and his or her manager.

The present study suggested that women managers were not necessarily devalued compared to their male counterparts. When female managers were clearly described as competent, they were evaluated more positively than their male counterparts, regardless of their interpersonally-related attributes (i.e., likeability). Competence was more valued in a supervisor's performance than likeability, but that likeability was a more important factor than competence when it came to a work relationship with one's manager. This 
underscores the innate desire to have a manager who is both a pleasure to work with (likeable) and good at his or her job (competent). This study demonstrated that when a manager had both competence and likeability, it was female managers who were evaluated more positively and preferred, not male managers. 


\section{References}

Bernstein, V., Hakel, M. D., \& Harlan, A. (1975). The college student as interviewer: A threat to generalizability? Journal of Applied Psychology, 60, 266-268.

Brenner, O. C., Tomkiewicz, J., \& Schein, V. E. (1989). The relationship between sex role stereotypes and requisite management characteristics revisited. The Academy of Management Journal, 32, 662-669.

Casciaro, T. \& Lobo, M. S. (2005). Competent jerks, lovable fools, and the formation of social networks. Harvard Business Review, 83, 92.

Dovidio, J. F., \& Gaertner, S. L. (2000). Aversive racism and selection decisions: 1989 and 1999. Directions in Psychological Science, 8, 101-105.

Eagly, A. H. (2005). Achieving relational authenticity in leadership: Does gender matter? The Leadership Quarterly, 16, 459-474.

Eagly, A. H. \& Johnson, B. T. (1990). Gender and leadership style: A meta-analysis. Psychological Bulletin, 108, 233-256.

Eagly, A. H. \& Karau, S. J. (2002). Role congruity theory of prejudice toward female leaders. Psychological Review, 109, 573-598.

Eagly, A. H., Karau, S. J., \& Makhijani, M. G. (1995). Gender and the effectiveness of leaders: A meta-analysis. Psychological Bulletin, 117, 125-145.

Eagly, A. H., Makhijani, M. G., \& Klonsky, B. G. (1992). Gender and the evaluation of leaders: A meta-analysis. Psychological Bulletin, 111, 3-22.

Fiske, S. T (1998). Stereotyping, prejudice, and discrimination. In D. T. Gilbert, S. T. Fiske, \& G. Lindzey, The handbook of social psychology $\left(4^{\text {th }}\right.$ ed., Vol. 2, pp. 357411). New York: McGraw-Hill.

Gordon, M. E., Slade, L. A. L., \& Schmitt, N. (1986). The 'science of the sophomore' revisited: From conjecture to empiricism. Academy of Management Review, 11, 91-207.

Heilman, M. E., (1983). Sex bias in work settings: The lack of fit model. Research in Organizational Behavior, 5, 269-298.

Heilman, M. E. \& Chen, J. J., (2005). Same behavior, different consequences: Reactions to men's and women's altruistic citizenship behavior. Journal of Applied Psychology, 90, 431-444. 
Heilman, M. E. \& Okimoto, T. G., (2007). Why are women penalized for success at male tasks?: The implied communality deficit. Applied Psychology, 92, 81-92.

Heilman, M. E., Wallen, A. S., Fuchs, D. \& Tamkins, M. M. (2004). Penalties for success: Reactions to women who succeed at male tasks. Journal of Applied Psychology, 89, 416-427.

Lyness, K. S. \& Heilman, M. E., (2006). When fit is fundamental: Performance evaluations and promotions of upper-level female and male managers. Journal of Applied Psychology, 91, 777-785.

Rudman, L. A., \& Glick, P. (1999). Feminized management and backlash toward agentic women: The hidden costs to women of a kinder, gentler image of middle managers. Journal of Personality and Social Psychology, 77, 1004-1010.

Social norm. (n.d.). Dictionary.com's 21st Century Lexicon. Retrieved June 2, 2011, from Dictionary.com website: http://dictionary.reference.com/browse/social norm

Stone, E. F., Stone, D. L., \& Dipboye, R. L. (1992). Stigmas in organizations: Race, handicaps, and physical unattractiveness. In K. Kelly (Ed.), Issues, theory, and research in industrial/organizational psychology (pp. 385-444). Amsterdam, Netherland: North-Holland.

Twenge, J. M. \& Campbell, S. M. (2008). Generational differences in psychological traits and their impact on the workplace. Journal of Managerial Psychology, 23, 862877.

United States Bureau of Labor Statistics. (2011). Women in the labor force: A databook (2011 Edition) [Data file]. Retrieved from http://www.bls.gov/cps/wlf-table112011.pdf 